University of Nebraska - Lincoln

DigitalCommons@University of Nebraska - Lincoln

2006

\title{
Differentiating Phonotactic Probability and Neighborhood Density in Adult Word Learning
}

Holly L. Storkel

University of Kansas

Jonna Armbrüster

University of Kansas

Tiffany Hogan

University of Nebraska - Lincoln, thogan2@unl.edu

Follow this and additional works at: https://digitalcommons.unl.edu/specedfacpub

Part of the Special Education and Teaching Commons

Storkel, Holly L.; Armbrüster, Jonna; and Hogan, Tiffany, "Differentiating Phonotactic Probability and Neighborhood Density in Adult Word Learning" (2006). Special Education and Communication Disorders Faculty Publications. 11.

https://digitalcommons.unl.edu/specedfacpub/11

This Article is brought to you for free and open access by the Department of Special Education and Communication Disorders at DigitalCommons@University of Nebraska - Lincoln. It has been accepted for inclusion in Special Education and Communication Disorders Faculty Publications by an authorized administrator of DigitalCommons@University of Nebraska - Lincoln. 


\title{
Differentiating Phonotactic Probability and Neighborhood Density in Adult Word Learning
}

\author{
Holly L. Storkel, Jonna Armbrüster, and Tiffany P. Hogan \\ University of Kansas, Lawrence
}

Corresponding author - Holly Storkel, Department of Speech-Language-Hearing: Sciences and Disorders, University of Kansas, 3001 Dole Human Development Center, 1000 Sunnyside Avenue, Lawrence, KS 66045-7555; email hstorkel@ku.edu

\begin{abstract}
Purpose: The purpose of this study was to differentiate effects of phonotactic probability, the likelihood of occurrence of a sound sequence, and neighborhood density, the number of words that sound similar to a given word, on adult word learning. A second purpose was to determine what aspect of word learning (viz., triggering learning, formation of an initial representation, or integration with existing representations) was influenced by each variable.

Method: Thirty-two adults were exposed to 16 nonwords paired with novel objects in a story context. The nonwords orthogonally varied in phonotactic probability and neighborhood density. Learning was measured following 1, 4, and 7 exposures in a picture-naming task. Partially correct (i.e., 2 of 3 phonemes correct) and completely correct responses (i.e., 3 of 3 phonemes correct) were analyzed together and independently to examine emerging and partial representations of new words versus complete and accurate representations of new words.

Results: Analysis of partially correct and completely correct responses combined showed that adults learned a lower proportion of high-probability nonwords than low-probability nonwords (i.e., high-probability disadvantage) and learned a higher proportion of high-density nonwords than low-density nonwords (i.e., high-density advantage). Separate analysis of partially correct responses yielded an effect of phonotactic probability only, whereas analysis of completely correct responses yielded an effect of neighborhood density only.

Conclusions: These findings suggest that phonological and lexical processing influence different aspects of word learning. In particular, phonotactic probability may aid in triggering new learning, whereas neighborhood density may influence the integration of new lexical representations with existing representations.
\end{abstract}

Keywords: word learning, vocabulary, phonotactic probability, neighborhood density

Recent models of spoken language processing incorporate two types of form representations: phonological and lexical (e.g., Dell, 1988; Gupta \& MacWhinney, 1997; Levelt, 1989; Luce, Goldinger, Auer, \& Vitevitch, 2000; Magnuson, Tanenhaus, Aslin, \& Dahan, 2003; McClelland \& Elman, 1986; Norris, 1994). Phonological representations correspond to knowledge of individual sounds with variation across models in the specific sound prop- erty chosen (e.g., phonetic features, context-specific allophones, phonemes). In contrast, lexical representations refer to knowledge of whole words. Most models also incorporate representation of referents or meanings of words - namely, semantic representations.

When a known word is encountered, it presumably activates these existing representations so that the word can be accurately recognized or produced. In contrast, 
when a novel word is encountered, it will activate matching phonological representations (assuming that the component sounds are known); however, it will not exactly match any existing lexical or semantic representation. This mismatch between the environment and stored representations in memory likely triggers the formation of a new lexical representation and a new semantic representation (e.g., Carpenter \& Grossberg, 1987; Gupta \& MacWhinney, 1997). That is, recognition that a novel word is unknown initiates the learning process. At that point, existing phonological representations may potentially aid in maintaining the sound sequence in working memory while a new lexical representation and a semantic representation are created. Moreover, these newly created lexical and semantic representations must form links with related existing lexical and semantic representations, thereby integrating the new representation with old representations in memory. These new representations and links are strengthened over repeated exposures to the novel word (e.g., Gupta \& MacWhinney, 1997). When the new representations and links stabilize, the word is considered mastered, although there may be evidence of gradient knowledge about the new word prior to ultimate mastery (e.g., Capone \& McGregor, 2005).

This hypothesized scenario is supported by data. Gaskell and Dumay (2003) attempted to differentiate the creation of an initial lexical representation from integration with existing lexical representations in adult word learning. They exposed adults to multisyllabic nonwords derived from real words (e.g., cathedruke derived from cathedral) in a phoneme-monitoring task, in which the adults listened to the nonwords and pressed a button if the nonword contained the specified target phoneme. Adults were also instructed to try to remember the nonwords. Formation of an initial lexical representation was tested in a recognition task. In the recognition task, participants heard a pair of nonwords (e.g., cathedruke and cathedruce) and had to decide which nonword they had heard previously (e.g., cathedruke). Integration of the new lexical representation with existing lexical representations was tested in a lexical-decision task that was administered pre- and postexposure. In the lexical-decision task, the original real words (e.g., cathedral) were presented, and participants had to judge whether these words were real words or nonwords. Of interest was the change in reaction time from the preexposure test to the postexposure test. If participants integrated the new lexical representation with existing lexical representations, there should be competition between the new word and the existing word, leading to slower lexical-decision times in the posttest as compared with the pretest. The recognition task results showed that adults accurately recognized the nonwords, indicating that they had created a new lexical representation following relatively minimal exposure (i.e., 12 presentations of the nonword). Moreover, recognition remained accurate fol- lowing a delay, suggesting that these new lexical representations were retained over time (i.e., after $24 \mathrm{hr}$ and 1 week). However, changes in the postexposure lexicaldecision task were not immediately observed. Evidence of competition in the postexposure lexical-decision task only emerged 3-7 days after initial exposure (both with and without additional exposure). Thus, integration of the new representation with existing representations required additional time. In summary, the learning of an initial representation appeared to occur rapidly, but the integration of the new representation with existing representations appeared to be protracted.

Taken together, word learning appears to comprise three distinct processes. The first process involves the recognition that a novel word was heard and the resultant triggering of learning. This process has received less attention in previous research, but it is likely critical in naturalistic word learning in which presentation of a novel word may not be highlighted in any way (e.g., "Here's a word you probably don't know"). Thus, the learner must detect the mismatch between the novel word and existing lexical representations to initiate learning. The second process involves the creation of a representation of the novel word. These first two processes appear to occur relatively rapidly. The third process involves the integration of the new representation with existing representations, which presumably is more protracted. We propose to build on the results of Gaskell and Dumay (2003) by investigating the influence of existing phonological and lexical representations on these different word learning processes, as indexed by partial versus complete responses.

It has been proposed that insights about processing within each representation can be inferred by observing the behavioral effects of two distinct, but related, form characteristics: phonotactic probability and neighborhood density (Vitevitch \& Luce, 1999). Phonotactic probability refers to the frequency of occurrence of individual sounds and sound combinations. It is thought that behavioral effects of phonotactic probability provide insights about the role of phonological representations in language processing (Vitevitch \& Luce, 1999). Neighborhood density refers to the number of words that sound similar to a given word. Behavioral effects of neighborhood density are presumed to reveal the influence of lexical representations on language processing (Vitevitch \& Luce, 1999). Findings from past studies are summarized in Table 1.

Although there are no published studies documenting the effects of phonotactic probability and neighborhood density on word learning by adults, there are numerous studies documenting the effect of each of these variables on recognition, production, and memory (see Table 1). In terms of phonotactic probability, adults recognize and name high-probability sound sequences more rapidly and accurately than low-probabil- 
Table 1. Summary of past research on phonotactic probability and neighborhood density effects.

\begin{tabular}{lllll}
\hline Sample & Recognition & Production & Memory & Word learning \\
\hline Adults & High-probability advantage & High-probability advantage & High-probability advantage & \\
& High-density disadvantage & High-density advantage & High-density advantage & \\
\multirow{2}{*}{ Children } & & High-probability advantagea & High-probability advantagea & High-probability/ High-density advantageb \\
& High-density disadvantage & High-density advantage & & \\
\hline
\end{tabular}

a Results based on nonword repetition tasks that contain elements of production and memory.

b Phonotactic probability effects have not been differentiated from neighborhood density effects.

ity sound sequences (e.g., Frisch, Large, \& Pisoni, 2000; Luce \& Large, 2001; Vitevitch, Armbruster, \& Chu, 2004; Vitevitch \& Luce, 1998, 1999). In addition, adults recall high-probability nonwords more accurately than lowprobability nonwords (Thorn \& Frankish, 2005; but see Roodenrys \& Hinton, 2002, who failed to find an effect of phonotactic probability). Taken together, phonological processing appears to entail a high-probability advantage in recognition, production, and memory by adults.

Turning to neighborhood density, adults recognize high-density words more slowly and less accurately than low-density words (e.g., Luce \& Large, 2001; Luce \& Pisoni, 1998; Vitevitch, 2002b; Vitevitch \& Luce, 1998, 1999). In contrast, adults produce high-density words more rapidly and accurately than low-density words (Vitevitch, 1997, 2002a) and recall high-density nonwords more accurately than low-density nonwords in serial recall tasks (Roodenrys \& Hinton, 2002). Thus, lexical processing appears to lead to a high-density disadvantage in recognition but a high-density advantage in production and memory.

Although no published study has examined the effect of phonotactic probability and neighborhood density on word learning by adults, there are several studies of the effect of phonotactic probability and neighborhood density on child word learning. These child studies are relevant to adult word learning because children show similar effects of phonotactic probability and neighborhood density on spoken language processing (see Table 1). In terms of phonotactic probability, children repeat highprobability nonwords more accurately than low-probability nonwords (e.g., Beckman \& Edwards, 2000; Edwards, Beckman, \& Munson, 2004; Gathercole, Frankish, Pickering, \& Peaker, 1999; Munson, 2001; Munson, Edwards, \& Beckman, 2005; Munson, Kurtz, \& Windsor, 2005; Munson, Swenson, \& Manthei, 2005). Thus, the available evidence suggests that phonological processing in children entails a high-probability advantage similar to adults. Turning to neighborhood density, children recognize and repeat high-density real words more slowly and less accurately than low-density real words (e.g., Garlock, Walley, \& Metsala, 2001; Metsala, 1997; Munson, Swenson, et al., 2005). In addition, children name high-density real words more accurately than low-density real words (German \& Newman, 2004; but see Newman \& German, 2002, 2005). This suggests that lexical processing in children entails a high-density disadvantage in recognition and a high-density advantage in production. This pattern of child findings is similar to that of adults.

The parallels between the adult and child recognition, production, and memory findings suggest that similarities may also be found between adult and child word learning. Word learning by typically developing preschool children appears to be influenced by phonotactic probability, neighborhood density, or both (Storkel, 2001, 2003, 2004a; Storkel \& Maekawa, 2005; Storkel \& Rogers, 2000). In a series of studies, children were exposed to nonwords that were high probability/high density (e.g., / pin/) and those that were low probability/low density (e.g., / moId/) in a story context. Learning of the nonwords was examined in a receptive picture-pointing task, a picture-naming task, or both. Results showed that children learned high-probability/ high-density nonwords more rapidly than low-probability/low-density nonwords across a variety of word types (i.e., nouns, verbs, and homonyms; Storkel, 2001; Storkel, 2003, 2004a; Storkel \& Maekawa, 2005; Storkel \& Rogers, 2000).

These child results establish a high phonotactic probability/high neighborhood density advantage in word learning by typically developing children; however, it is unclear whether this advantage is attributable to phonological or lexical processing because the stimuli were correlated in phonotactic probability and neighborhood density. Although this correlation is consistent with the structure of English (Storkel, 2004b; Vitevitch, Luce, Pisoni, \& Auer, 1999), it makes it difficult to assess the independent and interactive influence of phonological and lexical processing on word learning. In addition, no information is available to suggest what aspects of the word learning process (viz., triggering learning, formation of an initial representation, or integration with existing representations) are affected by phonological or lexical representations.

The goal of the present study was to disentangle the influence of phonological and lexical representations 
on adult word learning by examining learning of nonwords orthogonally varying in phonotactic probability and neighborhood density. The effect of these two variables on overall word learning will aid in determining whether phonological representations, lexical representations, neither, or both influence word learning by adults. A further question addressed by the current study is which word learning processes (i.e., triggering learning, formation of an initial representation, integration with existing representations) are affected by phonological or lexical representations. This issue was explored by examining the effect of phonotactic probability and neighborhood density on partially correct versus completely correct responses. We assume that a partially correct response will index an early stage of word learning, providing information about the factors that affect triggering of learning and creation of an initial representation. In contrast, completely correct responses will index a later stage of word learning, providing information about the factors that affect integration of the new representation with existing representations. Thus, analysis of these two types of responses will allow exploration of the specific variables that affect learning at each stage.

\section{Method}

\section{Participants}

Thirty-two native English-speaking adults (mean age $=20$ years, $S D=3$ years, range $=18-36$ years) from the University of Kansas student community participated. All participants reported no history of speech, hearing, or learning disorder and received partial course credit in exchange for participation.

\section{Materials}

Phonotactic probability. The nonwords to be learned differed on two independent variables: phonotactic probability and neighborhood density. Phonotactic probability was computed using a 20,000 word electronic dictionary (Webster's Seventh New Collegiate Dictionary, 1967) containing phonemic transcriptions of American English. Two measures of phonotactic probability were computed: positional segment frequency and biphone frequency. Positional segment frequency is the frequency that a given sound occurs in a given word position, in which position is defined from the left edge of the word (e.g., first sound, second sound). To compute this, the sum of the log frequencies of all the words in the dictionary containing a particular sound in a particular position of a word was divided by the sum of the log frequencies of all the words in the dictionary containing any sound in the same word position (Storkel, 2004b). Biphone frequency is the likelihood that two adjacent sounds co-occur in a given word position (e.g., first + second sounds, second + third sounds). This is calculated by taking the sum of the log frequencies of all the words containing a particular biphone in a particular word position and dividing this sum by the sum of the log frequencies of all the words containing any phoneme in the same word position (Storkel, 2004b).

Positional segment frequency and biphone frequency were computed for all legal CVC patterns in American English. Each CVC was then categorized as high or low using a median split. Values above the median were classified as high, and values at or below the median were classified as low. When the classification by positional segment frequency disagreed with that of biphone frequency, the CVC was eliminated from the potential stimulus pool.

Neighborhood density. Neighborhood density was computed by counting the number of words in the dictionary that differed from the target by a one phoneme addition, deletion, or substitution. As with phonotactic probability, density was computed for all legal CVCs, and each CVC was categorized as high or low based on a median split.

Sixteen nonwords were chosen with four nonwords in each of the following conditions: (a) high probability / high density, (b) high probability/low density, (c) low probability/high density, and (d) low probability/low density. Means and standard deviations for positional segment frequency, biphone frequency, and neighborhood density for each condition are shown in Table 2. The specific nonwords selected are shown in Table 3.

Novel objects. The selected nonwords were paired with pictures of novel objects that adults were not able to name with one word. These novel objects were previously used in studies of preschool children (Storkel, 2004a). Semantic category was matched across the four phonotactic probability/neighborhood density

Table 2. Phonological and lexical characteristics of the stimuli.

\begin{tabular}{lcccc}
\hline \multicolumn{2}{c}{$\begin{array}{c}\text { High phonotactic } \\
\text { probability } \\
\text { High }\end{array}$} & $\begin{array}{c}\text { Low } \\
\text { density }\end{array}$ & $\begin{array}{c}\text { Low phonotactic } \\
\text { probability }\end{array}$ \\
density & density & Low \\
Measure & density & \\
\hline $\begin{array}{l}\text { Positional segment frequency } \\
M\end{array}$ & 0.16 & 0.15 & 0.09 & 0.09 \\
SD & 0.02 & 0.03 & 0.01 & 0.01 \\
Biphone frequency & & & & \\
$M$ & 0.0056 & 0.0066 & 0.0017 & 0.0010 \\
SD & 0.0050 & 0.0061 & 0.0007 & 0.0003 \\
Neighborhood density & & & & \\
$M$ & 14 & 5 & 14 & 5 \\
SD & 2 & 1 & 2 & 1 \\
\hline
\end{tabular}


Table 3. Form and referent characteristics of the stimuli.

\begin{tabular}{|c|c|c|c|c|c|c|c|c|}
\hline \multicolumn{2}{|c|}{$\begin{array}{l}\text { High phonotacti } \\
\text { probability }\end{array}$} & \multicolumn{2}{|c|}{$\begin{array}{l}\text { L Low phonotactic } \\
\text { probability }\end{array}$} & \multirow[b]{2}{*}{ Category } & \multirow[b]{2}{*}{ Referent 1} & \multirow[b]{2}{*}{ Referent 2} & \multirow[b]{2}{*}{ Referent 3} & \multirow[b]{2}{*}{ Referent 4} \\
\hline $\begin{array}{l}\text { High } \\
\text { density }\end{array}$ & $\begin{array}{l}\text { Low } \\
\text { y density }\end{array}$ & $\begin{array}{l}\text { High } \\
\text { density }\end{array}$ & $\begin{array}{l}\text { Low } \\
\text { density }\end{array}$ & & & & & \\
\hline pim & han & jerm & favg & $\begin{array}{l}\text { Candy } \\
\text { machine }\end{array}$ & $\begin{array}{l}\text { Red candy }+ \\
1 \text { chute (created) }\end{array}$ & $\begin{array}{l}\text { Blue candy }+ \\
2 \text { chutes (created) }\end{array}$ & $\begin{array}{l}\text { Yellow candy }+ \\
1 \text { chute (created) }\end{array}$ & $\begin{array}{l}\text { Green candy + } \\
1 \text { chute (created) }\end{array}$ \\
\hline mek & jib & hif & waf & Horn & $\begin{array}{l}\text { Orange trumpet bell } \\
\text { pointing down } \\
\text { (Geisel \& Geisel, 1954) }\end{array}$ & $\begin{array}{l}\text { Yellow hand-held } \\
\text { tuba (Geisel \& } \\
\text { Geisel, 1954) }\end{array}$ & $\begin{array}{l}\text { Red saxophone } \\
\text { pointing down } \\
\text { (Geisel \& Geisel, 1954) }\end{array}$ & $\begin{array}{l}\text { Blue oboe pointing } \\
\text { upward (Geisel } \\
\text { \& Geisel, 1954) }\end{array}$ \\
\hline wæd & paib & naut & mug & Pet & $\begin{array}{l}\text { Green gerbil + antenna } \\
\text { (DeBrunhoff, 1981) }\end{array}$ & $\begin{array}{l}\text { Purple mouse-bat } \\
\text { (Mayer, 1992) }\end{array}$ & $\begin{array}{l}\text { Yellow frog-bat } \\
\text { (Mayer, 1992) }\end{array}$ & $\begin{array}{l}\text { Orange elephant } \\
\text { mouse (Mayer, 1992) }\end{array}$ \\
\hline
\end{tabular}

Pairing of nonwords to referents was counterbalanced across participants.

conditions. The pairing of nonwords with objects was counterbalanced across participants. Table 3 provides a description of the novel objects.

Story exposure. The 16 nonword-object pairs were divided into two sets of 8 with phonotactic probability/ neighborhood density condition and semantic category balanced across sets. Each set of nonword-object pairs was embedded in one of two stories, with the order of presentation of the two stories being counterbalanced across participants. Each story consisted of three distinct episodes.

Each episode in the two stories contained a set of six visual scenes and a corresponding auditory narrative. The scenes and narrative frame were used in previous studies of child word learning (Storkel, 2004a). The Appendix provides an example of the visual scenes and narrative for Story Episode 1. The first visual scene and narrative provided an introduction to the two main characters and a central activity (e.g., selecting objects to take to another location). The four intermediate visual scenes and corresponding narrative provided exposure to the nonword-object pairs, with semantically related objects being presented simultaneously. In these four visual scenes, the two main characters were presented interacting with the novel objects. The accompanying auditory narrative presented the corresponding nonword embedded in a sentence. The sixth and final scene and narrative provided the conclusion of the activity. Across episodes, the main characters remained the same, but the central activity (e.g., selecting objects vs. hiding objects) changed. In addition, the number of exposures to the nonword-object pairs varied across episodes: Episode 1 provided one exposure to each nonword-object pair, whereas Episodes 2 and 3 provided three exposures to each pair. Thus, the $\mathrm{cu}-$ mulative number of exposures following each episode was one (Episode 1), four (Episode 2), and seven (Episode 3$)$.

Visual scenes were digitized and edited. The auditory narrative was recorded in a soundproof booth, digitized, and edited. The speaking rate, measured in syllables per second, was similar across the phonotactic probability/ neighborhood density conditions, all $\mathrm{Fs}(1,56)<1.0, p>$ .70. In addition, under the same listening conditions as the participants, two naive listeners transcribed the nonwords as intended, demonstrating appropriate quality of the audio recordings.

Measure of learning. A picture-naming task was used to assess learning of the nonword-object pairs. In this task, a picture of one of the novel objects appeared on the computer screen and the participant attempted to produce the corresponding nonword. This task was given four times per story: before the story to obtain a baseline and following each of the three episodes. The responses were phonetically transcribed and scored. A response was scored as partially correct if two of the three phonemes were produced in the correct word position. A partially correct response was thought to result from an emerging or partial representation of the new word. A response was scored as completely correct if all three phonemes were produced correctly in the correct order. A completely correct response was thought to reflect a complete and accurate representation of the new word. These two types of responses were combined in one analysis to afford comparison to past child word learning studies (Storkel, 2001, 2003, 2004a; Storkel \& Maekawa, 2005; Storkel \& Rogers, 2000). In addition, each type of response was analyzed independently to examine the effect of phonotactic probability and neighborhood density on partial (i.e., early-stage word learning) versus complete representations (i.e., late-stage word learning). 
Consonant-to-consonant transcription reliability and scoring reliability were computed for $22 \%$ of the participants. Interjudge transcription reliability was 99\% (SD $=1 \%$, range $=96 \%-100 \%$ ). Interjudge scoring reliability was $99 \%(S D=1 \%$, range $=97 \%-100 \%)$.

\section{Procedure}

Each participant was seated in front of a computer that presented auditory stimuli over headphones (i.e., Sennheiser HMD280-13). Participant responses were recorded using a head-mounted microphone (i.e., Sennheiser HMD280-13) and a digital tape recorder (i.e., Tascam DA40). Presentation of the auditory and visual stimuli was controlled by the computer using DirectRT software (Jarvis, 2002).

The study required one 45-min session. The session started with the baseline naming task for the first story. The eight objects for the first story were randomly presented on the computer screen, and participants were instructed to guess the name of each object. Responses were audio recorded. Next, the first episode of the first story was presented. The introductory scene and the concluding scene for each story episode were always presented first and last, respectively. The intermediate four scenes that provided exposure to the nonword-object pairs were presented in random order as determined by the DirectRT software. Although the presentation order was random, the coherence of the story was preserved because each scene related to an overall routine (e.g., selecting objects to take to another location), and each scene made no reference to the other scenes. Refer to the Appendix for details of the first story episode. Then, the picture-naming task was readministered with instructions for the participant to attempt to remember the names of the objects introduced in the story. The second and third episodes of the first story and corresponding naming tasks followed in the same manner. A break occurred after the first story, and then the second story was completed following the same procedure.

\section{Results}

\section{Partially Correct and Completely Correct Responses}

The first analysis examined the effect of phonotactic probability and neighborhood density on both partially correct (i.e., two of three phonemes) and completely correct (i.e., three of three phonemes) responses combined for comparison to previous studies. The dependent variable was the proportion correct (i.e., two to three of three phonemes) in the naming task for each phonotactic probability/neighborhood density condition (i.e., high probability/high density, high proba- bility/low density, low probability/high density, and low probability/low density) at each exposure (i.e., Exposures 1,4 , and 7). These data were submitted to a 2 (phonotactic probability) $\times 2$ (neighborhood density) $\times$ 3 (cumulative exposure) repeated-measures analysis of variance (ANOVA).

The main effects of phonotactic probability and neighborhood density were significant, $F(1,31)=6.07, p$ $<.05, \eta_{\mathrm{p}}{ }^{2}=.164$, for phonotactic probability, and $F(1,31)$ $=11.71, p<.01, \eta_{\mathrm{p}}{ }^{2}=.274$, for neighborhood density. The effect of exposure also was significant, $F(2,62)=131.80$, $p<.001, \eta_{\mathrm{p}}^{2}=.810$. There were no significant interactions of phonotactic probability and neighborhood density, $F(1,31)=0.18, p>.65, \eta_{\mathrm{p}}{ }^{2}=.006$; phonotactic probability and exposure, $F(2,62)=1.98, p>.10, \eta_{\mathrm{p}}{ }^{2}=.060$; neighborhood density and exposure, $F(2,62)=0.28, p>$ $.70, \eta_{\mathrm{p}}{ }^{2}=.009$; or neighborhood density and phonotactic probability and exposure, $F(2,62)=1.61, p>.20, \eta_{\mathrm{p}}{ }^{2}$ $=.049$.

Considering phonotactic probability first, adults learned a lower proportion of high-probability nonwords $(M=0.42, S D=0.36, S E M=0.06)$ than low-probability nonwords $(M=0.47, S D=0.35, S E M=0.06)$. Figure 1 shows the naming responses to high- and lowprobability nonwords at each exposure for high-density (top panel) and low-density (bottom panel) nonwords. As can be seen from this figure and the lack of any significant interactions, this high-probability disadvantage was relatively consistent across exposures and neighborhood density, although the size of the disadvantage did show some variability. This high-probability disadvantage was counter to past findings from child word learning studies (Storkel, 2001, 2003, 2004a; Storkel \& Maekawa, 2005; Storkel \& Rogers, 2000).

Turning now to neighborhood density, adults learned a higher proportion of high-density nonwords $(M=0.48$, $S D=0.35, S E M=0.06)$ than low-density nonwords $(M=$ $0.41, S D=0.35, S E M=0.06$ ). Figure 2 shows the naming responses to high- and low-density nonwords at each exposure for high-probability (top panel) and low-probability (bottom panel) nonwords. As with phonotactic probability, the high-density advantage was relatively consistent across exposures and phonotactic probability. This high-density advantage was consistent with past word learning studies (Storkel, 2001, 2003, 2004a; Storkel \& Maekawa, 2005; Storkel \& Rogers, 2000).

Finally, accuracy increased with the number of exposures, as is typical in learning tasks. Specifically, lowest accuracy was observed following one exposure $(M$ $=0.18, S D=0.21, S E M=0.04)$, intermediate accuracy following four exposures $(M=0.49, S D=0.32, S E M=$ $0.06)$, and highest accuracy following seven exposures $(M=0.68, S D=0.32, S E M=0.06)$. Planned comparisons showed that accuracy at each increasing exposure level was significantly higher than the previous level, all Fs(1, 31) $>74$, all $p \mathrm{~s}<.001$, all $\eta_{\mathrm{p}}{ }^{2} \mathrm{~s}>.70$. 

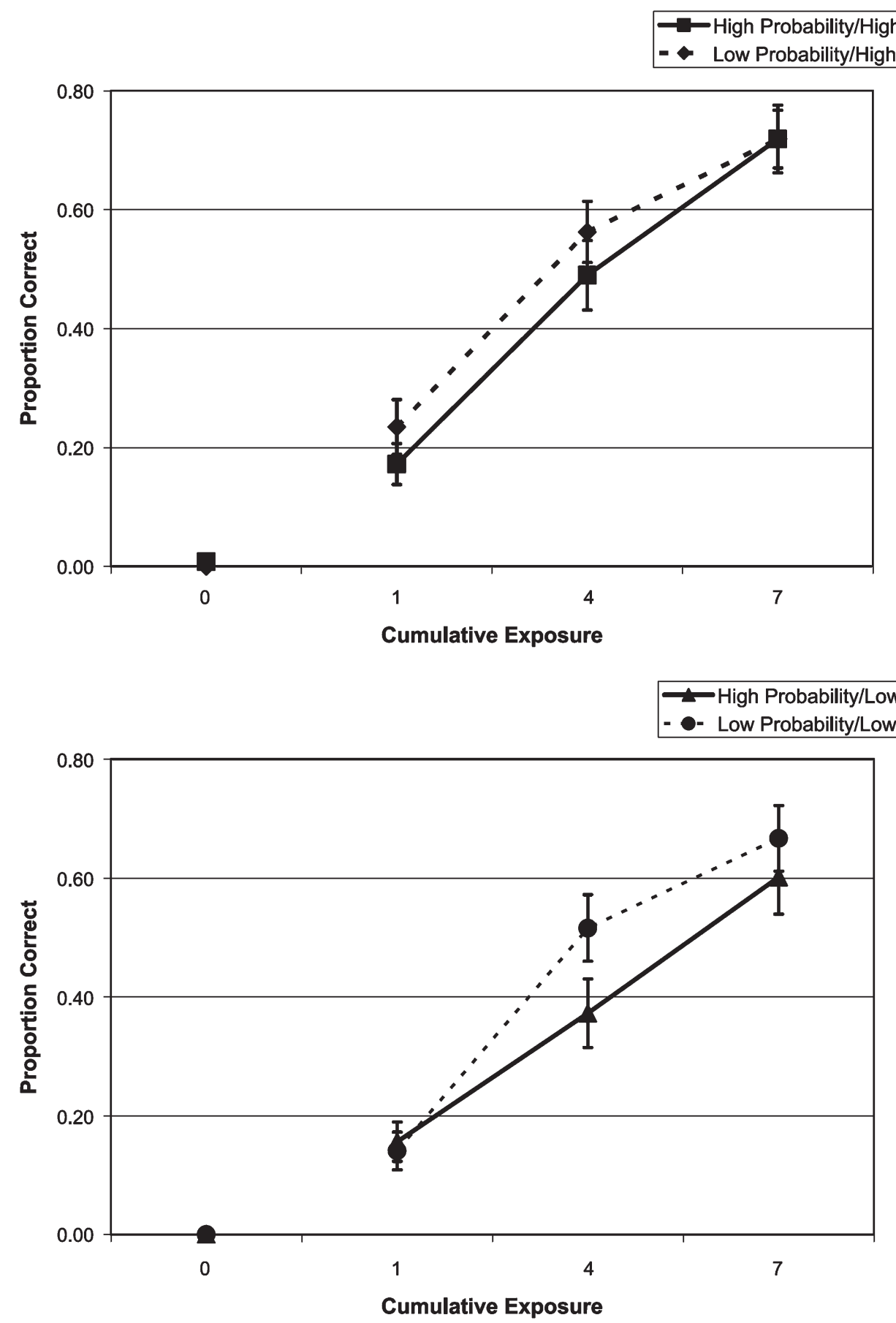

Figure 1. Proportion of correct responses (partial + complete) by cumulative exposure for high phonotactic probability (triangles, squares) versus low phonotactic probability (circles, diamonds) for high-density (top panel) and low-density nonwords (bottom panel). Note that these are the same data as in Figure 2 but rearranged to afford easier comparison between high versus low phonotactic probability.

\section{Partially Correct Responses}

The second analysis examined the effect of phonotactic probability and neighborhood density on partially correct responses to determine whether each variable had a similar effect on early word learning.
The dependent variable was the proportion of partially correct responses (i.e., two of three phonemes) in the naming task for each phonotactic probability/neighborhood density condition (i.e., high probability/high density, high probability/low density, low probability/high density, and low probability/low density) at 

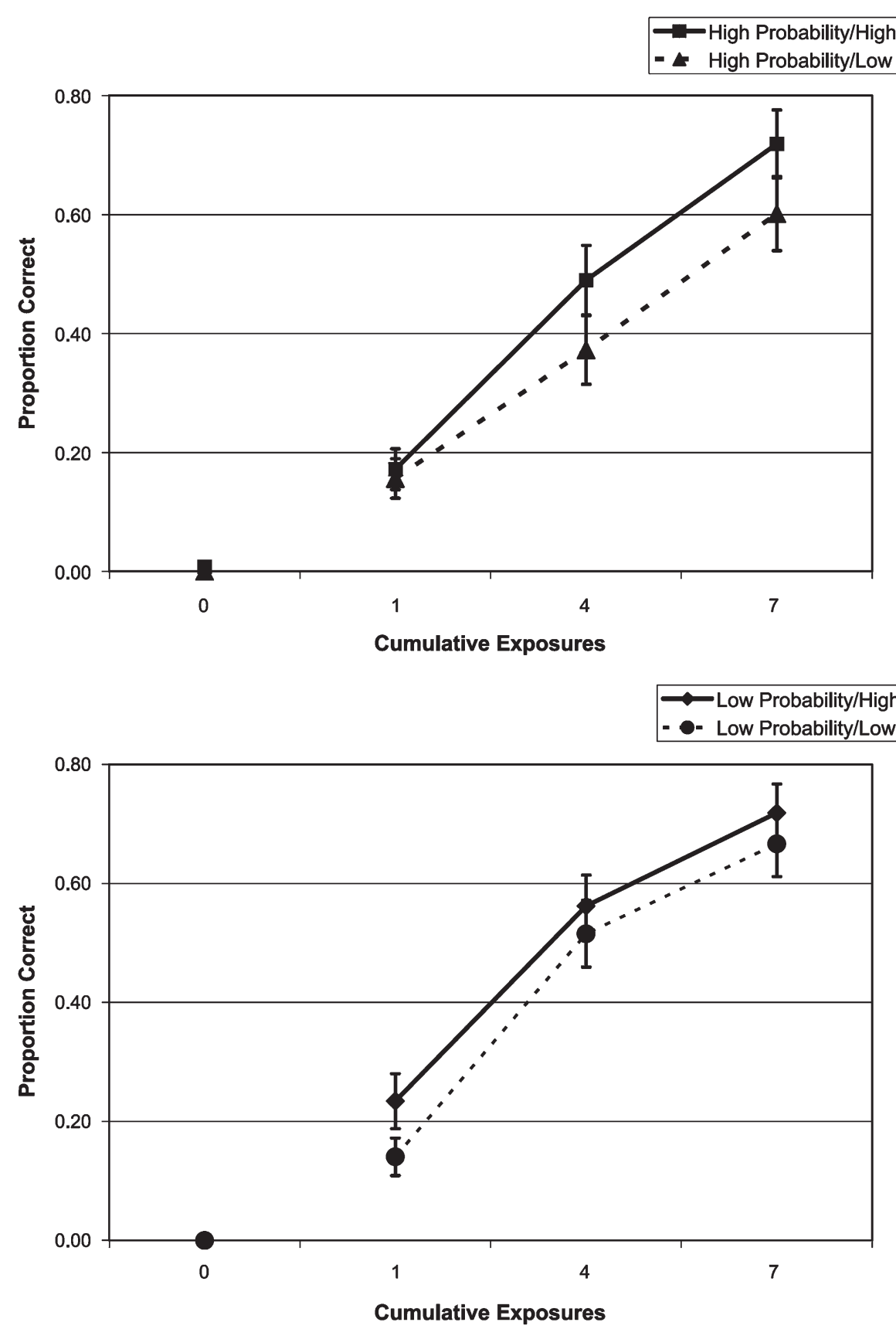

Figure 2. Proportion of correct responses (partial + complete) by cumulative exposure for high density (diamonds, squares) versus low density (circles, triangles) for high-probability (top panel) and low-probability nonwords (bottom panel). Note that these are the same data as in Figure 1 but rearranged to afford easier comparison of high versus low density.

each exposure (i.e., Exposures 1, 4, and 7). These data were submitted to a 2 (phonotactic probability) $\times 2$ (neighborhood density) $\times 3$ (cumulative exposure) repeated-measures ANOVA.

The main effect of phonotactic probability was significant, $F(1,31)=6.37, p<.05, \eta_{p}^{2}=.170$. The main effect of neighborhood density was not significant, $F(1,31)=$ $1.14, p>.25, \eta_{\mathrm{p}}{ }^{2}=.036$. The main effect of exposure was significant, $F(2,62)=13.23, p<.001, \eta_{p}^{2}=.299$. There were no significant interactions of phonotactic probability and neighborhood density, $F(1,31)=2.21, p>.10, \eta_{\mathrm{p}}{ }^{2}$ $=.067$; phonotactic probability and exposure, $F(2,62)=$ $1.09, p>.30, \eta_{\mathrm{p}}^{2}=.034$; neighborhood density and exposure, $F(2,62)=1.50, p>.20, \eta_{\mathrm{p}}{ }^{2}=.046$; or neighborhood density and phonotactic probability and exposure, $F(2$, 62) $=1.08, p>.30, \eta_{\mathrm{p}}^{2}=.034$.

In terms of phonotactic probability, adults formed fewer partial representations for high-probability non- 

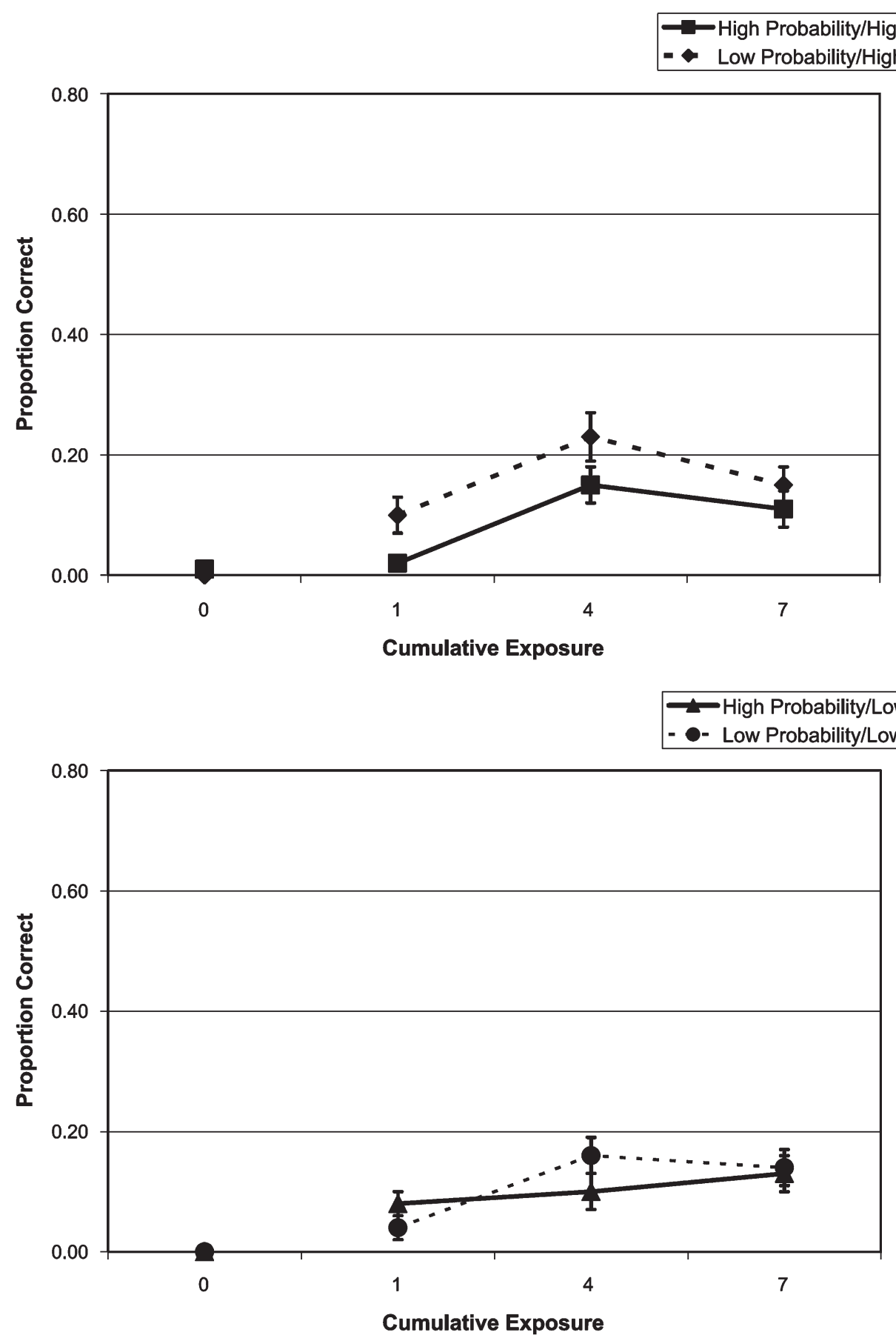

Figure 3. Proportion of partially correct responses (i.e., two of three phonemes correct) by cumulative exposure for high phonotactic probability (triangles, squares) versus low phonotactic probability (circles, diamonds) for high-density (top panel) and low-density nonwords (bottom panel). Note that these are the same data as in Figure 4 but rearranged to afford easier comparison between high versus low phonotactic probability.

words $(M=0.10, S D=0.15, S E M=0.03)$ than for lowprobability nonwords $(M=0.14, S D=0.18, S E M=0.03)$. Figure 3 shows the partially correct responses to highand low-probability nonwords at each exposure for high-density (top panel) and low-density (bottom panel) nonwords. In this figure, there is a clear high-probability disadvantage for high-density nonwords. Despite the lack of a significant interaction, the effect of phonotactic probability for low-density nonwords is reduced relative to the effect for high-density nonwords. The signif- 

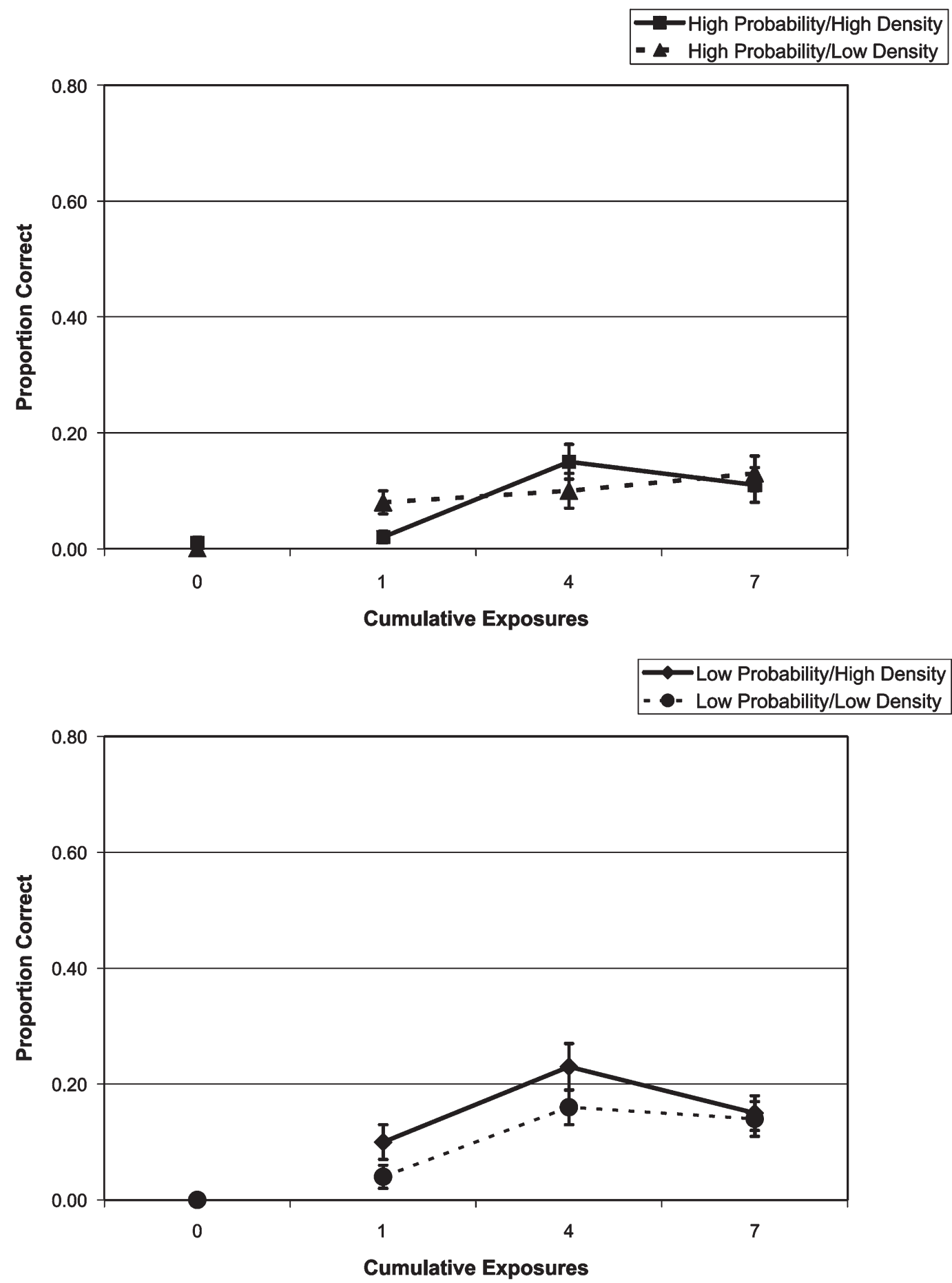

Figure 4. Proportion of partially correct responses (i.e., two of three phonemes correct) by cumulative exposure for high density (diamonds, squares) versus low density (circles, triangles) for high-probability (top panel) and low-probability nonwords (bottom panel). Note that these are the same data as in Figure 3 but rearranged to afford easier comparison of high versus low density.

icant main effect of phonotactic probability on partially correct responses suggests that phonotactic probability may play a role in the earliest stages of word learning.

In terms of neighborhood density, adults formed partial representations relatively equivalently for highdensity $(M=0.13, S D=0.18, S E M=0.03)$ and low-den- sity nonwords $(M=0.11, S D=0.15, S E M=0.03)$. Figure 4 shows the partially correct responses to high- and low-density nonwords at each exposure for high-probability (top panel) and low-probability (bottom panel) nonwords. The effect of neighborhood density did not show a clear pattern, suggesting that neighborhood den- 
sity may be less critical in the earliest stages of word learning.

Finally, partially correct responses increased from one exposure $(M=0.06, S D=0.13, S E M=0.02)$ to four exposures $(M=0.16, S D=0.18, S E M=0.03)$ and then leveled off at seven exposures $(M=0.13, S D=0.18$, SEM $=0.03$ ). Planned comparisons showed that the difference between one and four exposures was significant, $F(1,31)$ $=30.83, p<.001, \eta_{\mathrm{p}}{ }^{2}=.499$, whereas the difference between four and seven exposures was not significant, $F(1$, $31)=1.28, p>.25, \eta_{\mathrm{p}}^{2}=.040$.

\section{Completely Correct Responses}

The final analysis examined the effect of phonotactic probability and neighborhood density on completely correct responses to determine whether each variable had a similar effect on late word learning. The dependent variable was the proportion of completely correct responses (i.e., three of three phonemes) in the naming task for each phonotactic probability/neighborhood density condition (i.e., high probability/high density, high probability/low density, low probability/high density, and low probability/low density) at each exposure (i.e., Exposures 1, 4, and 7). These data were submitted to a 2 (phonotactic probability) $\times 2$ (neighborhood density) $\times 3$ (cumulative exposure) repeated-measures ANOVA.

The main effect of phonotactic probability was not significant, $F(1,31)=0.64, p>.40, \eta_{\mathrm{p}}^{2}=.020$. In contrast, the main effect of neighborhood density was significant, $F(1,31)=6.23, p<.05, \eta_{\mathrm{p}}^{2}=.167$, as was the main effect of exposure, $F(2,62)=88.88, p<.001, \eta_{p}{ }^{2}=.741$. One of the interactions approached significance, namely, the interaction of phonotactic probability and neighborhood density, $F(1,31)=3.35, p=.08, \eta_{\mathrm{p}}^{2}=.098$. In contrast, there were no significant interactions of phonotactic probability and exposure, $F(2,62)=0.28, p>.75, \eta_{\mathrm{p}}{ }^{2}=$ .009 ; neighborhood density and exposure, $F(2,62)=1.79$, $p>.15, \eta_{\mathrm{p}}{ }^{2}=.055$; or neighborhood density and phonotactic probability and exposure, $F(2,62)=0.26, p>.75$, $\eta_{\mathrm{p}}^{2}=.008$.

In terms of phonotactic probability, adults formed an equivalent number of complete representations for high-probability $(M=0.32, S D=0.31, S E M=0.05)$ and low-probability nonwords $(M=0.34, S D=0.33, S E M=$ 0.06 ). Figure 5 shows the completely correct responses to high- and low-probability nonwords at each exposure for high-density (top panel) and low-density (bottom panel) nonwords. In this figure, there is no apparent effect of phonotactic probability for high-density or low-density nonwords. The lack of a significant main effect of phonotactic probability suggests that phonological representations may play a lesser role, if any, in later stages of word learning.
In terms of neighborhood density, adults formed more complete representations for high-density nonwords $(M=0.36, S D=0.33, S E M=0.06)$ than for lowdensity nonwords $(M=0.30, S D=0.31, S E M=0.05)$. Figure 6 shows the completely correct responses to highand low-density nonwords at each exposure for highprobability (top panel) and low-probability (bottom panel) nonwords. There is a high-density advantage for high-probability nonwords, $F(1,31)=8.94, p<.01, \eta_{\mathrm{p}}{ }^{2}$ $=.224$. In contrast, there is no apparent effect of neighborhood density for low-probability nonwords, $F(1,31)$ $=0.42, p>.50, \eta_{\mathrm{p}}{ }^{2}=.013$. Thus, the near significant interaction of phonotactic probability and neighborhood density may be attributable to this asymmetry in the high-density advantage across high-probability versus low-probability nonwords, although this effect warrants replication. The significant main effect of neighborhood density suggests that this variable may play a critical role in later stages of word learning.

Finally, completely correct responses increased from one exposure $(M=0.12, S D=0.17, S E M=0.03)$ to four exposures $(M=0.32, S D=0.27, S E M=0.05)$ and from four exposures to seven exposures $(M=0.54, S D=0.34$, $S E M=0.06$ ). Planned comparisons showed that accuracy at each increasing exposure level was significantly higher than the previous level, all $F \mathrm{~s}(1,31)>54$, all $p \mathrm{~s}<$ .001 , all $\eta_{\mathrm{p}}^{2}>.60$.

\section{Discussion}

The goals of this study were to examine the role of phonological and lexical representations in adult word learning and to attempt to determine which aspects of word learning are influenced by each type of representation. The results for the combined analysis of partially correct and completely correct responses showed a high phonotactic probability disadvantage and a high neighborhood density advantage, indicating that both phonological and lexical representations influence word learning in a unique way. Moreover, each representation appeared to influence a different aspect of word learning as revealed through the separate analysis of partially correct and completely correct responses. Specifically, only phonotactic probability influenced partially correct responses. In contrast, only neighborhood density influenced completely correct responses. This pattern suggests that phonological representations may play a role in processes associated with early word learning, whereas lexical representations may play a role in processes associated with later word learning.

\section{Locus of the Phonotactic Probability Effect}

As shown in Table 4, past studies of adults and children generally have shown a high-probability advan- 

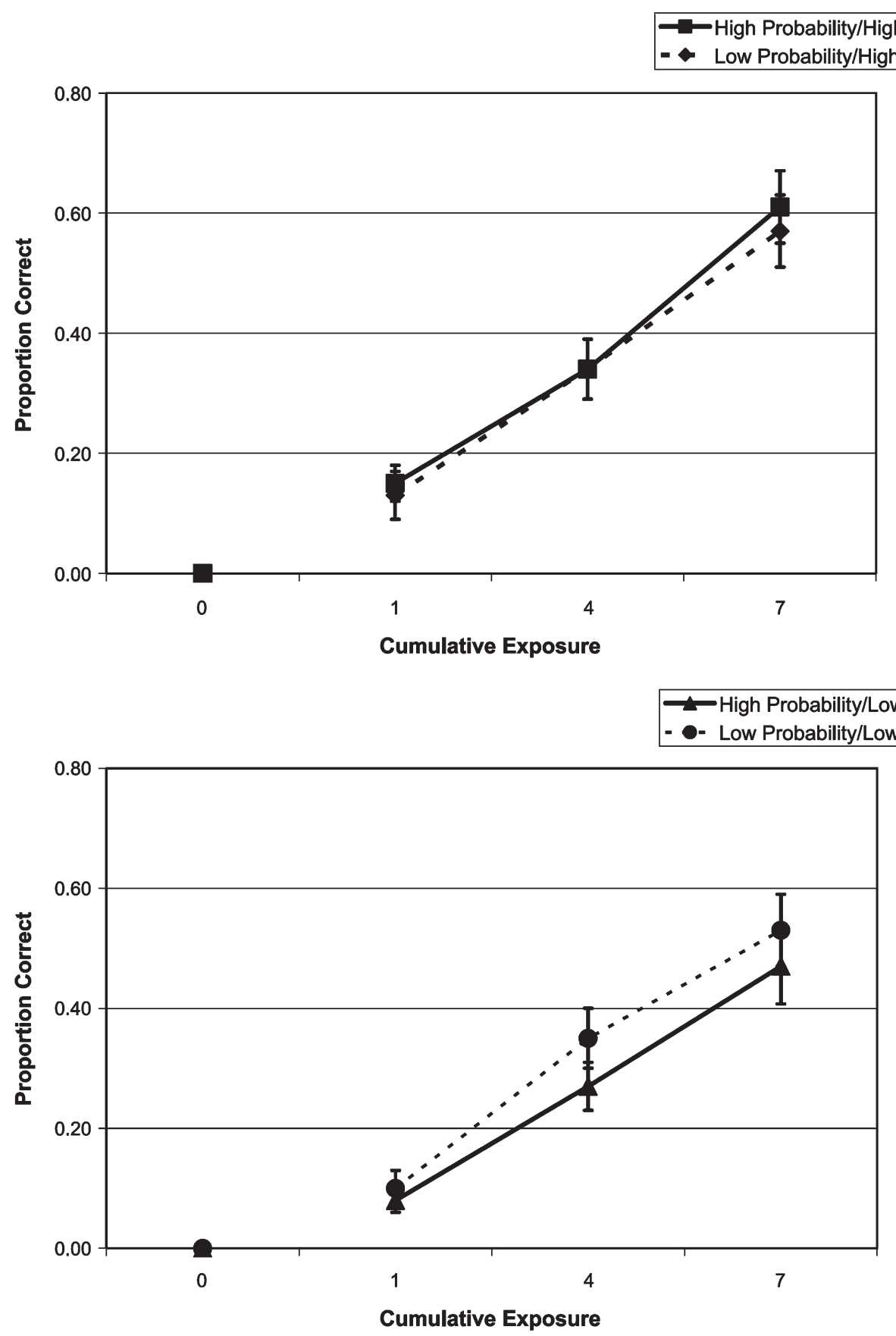

Figure 5. Proportion of completely correct responses (i.e., three of three phonemes correct) by cumulative exposure for high phonotactic probability (triangles, squares) versus low phonotactic probability (circles, diamonds) for high-density (top panel) and low-density nonwords (bottom panel). Note that these are the same data as in Figure 6 but rearranged to afford easier comparison between high versus low phonotactic probability.

tage in recognition, production, and serial recall. Thus, our finding of a high-probability disadvantage in word learning is particularly striking because, to our knowledge, this is the first report of a high-probability disadvantage in normal language processing. Given this difference between past studies of recognition, production, and serial recall and this study, the high-probability dis- advantage in word learning is not likely attributable to recognition, production, or working memory influences on word learning, although this was not directly tested. Instead, this high-probability disadvantage may be specific to word learning, and therefore it is likely attributable to a process that primarily occurs when learning new words. 

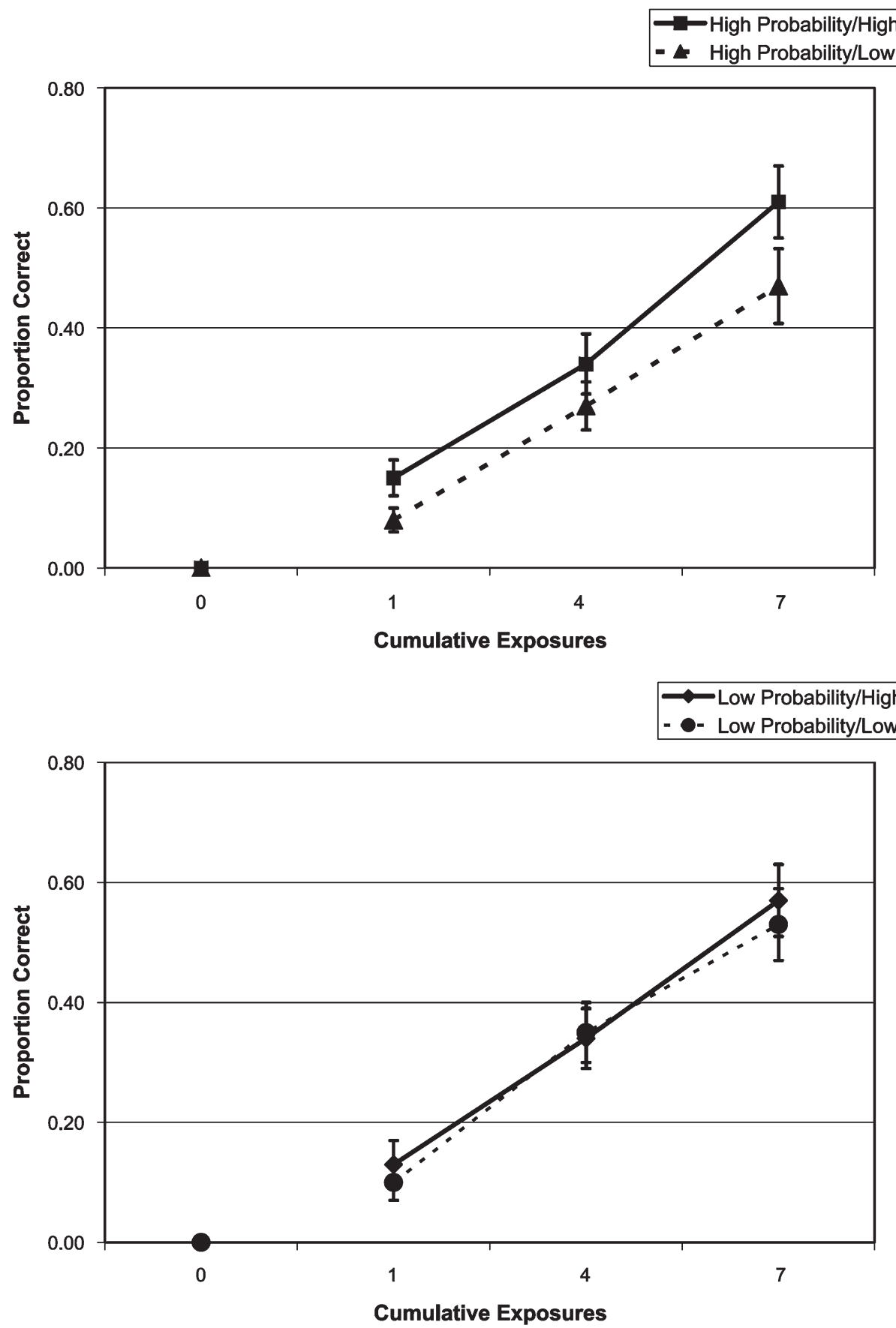

Figure 6. Proportion of completely correct responses (i.e., three of three phonemes correct) by cumulative exposure for high density (diamonds, squares) versus low density (circles, triangles) for high-probability (top panel) and low-probability nonwords (bottom panel). Note that these are the same data as in Figure 5 but rearranged to afford easier comparison of high versus low density.

One process that is unique to word learning is the triggering of the formation of a new representation in long-term memory. That is, when listening to speech, presentation of a novel word may not be highlighted in any way (e.g., "Here's a word you probably don't know"). Thus, the listener must have some way of determining which words are known, thereby accessing ex- isting stored representations, and which words are new, thereby initiating learning through the creation of new representations. If such a process did not exist, then listeners would be forced to process all incoming words as either known or new. In fact, several types of computational models include some type of process to trigger new learning to allow for differential processing of 
Table 4. Integration of current results with those of past research on phonotactic probability and neighborhood density effects.

\begin{tabular}{lllll}
\hline Sample & Recognition & Production & Memory & Word learning \\
\hline Adults & High-probability advantage & High-probability advantage & High-probability advantage & High-probability disadvantage \\
& High-density disadvantage & High-density advantage & High-density advantage & High-density advantage \\
\multirow{2}{*}{ Children } & & High-probability advantage ${ }^{a}$ & High-probability advantagea & High-probability/High-density advantage ${ }^{b}$ \\
& High-density disadvantage & High-density advantage & & \\
\hline
\end{tabular}

a Results based on nonword repetition tasks that contain elements of production and memory.

b Phonotactic probability effects have not been differentiated from neighborhood density effects.

known versus new words. For example, adaptive resonance theory relies on a mismatch between input from the environment and stored representations in longterm memory to identify novel events and to trigger the creation of a new representation in long-term memory for that event (e.g., Carpenter \& Grossberg, 1987).

We hypothesize that phonotactic probability may influence triggering of word learning. In particular, highprobability novel words will be more "word-like" than low-probability novel words (e.g., Frisch et al., 2000; Vitevitch, Luce, Charles-Luce, \& Kemmerer, 1997). In this way, high-probability novel words may be deceptively similar to many other known sound sequences in the language, whereas low-probability novel words will stand apart from other sound sequences as unique. Based on this deceptive word-likeness, learning may not be triggered on first exposure to a high-probability sound pattern but may be immediately triggered on first exposure to a low-probability sound pattern. Thus, learning a high-probability sound sequence may require more exposures than learning a low-probability sound sequence because there is a lag between first exposure and the creation of a new representation. Consistent with this hypothesis, Gaskell and Dumay (2003) provided evidence that novel words can activate the representation of phonologically similar real words, rather than triggering the formation of a new representation. The current results extend these findings by suggesting asymmetry between high- and low-probability novel words, with high-probability novel words being more likely to activate real words and low-probability novel words being more likely to trigger new learning.

\section{Locus of the Neighborhood Density Effect}

As previously described (see Table 4), neighborhood density appears to lead to a high-density disadvantage in recognition but a high-density advantage in production and serial recall (Roodenrys \& Hinton, 2002; Vitevitch, 2002a). Thus, the high-density advantage observed in adult word learning is consistent with the findings from production and serial recall. Therefore, it is possi- ble that the observed high-density advantage in word learning is attributable to production or working memory processes rather than to a process specific to word learning. For example, neighborhood density may have influenced production of the nonwords at test, rather than the word learning process itself. This seems unlikely because past word learning studies show similar effects of correlated phonotactic probability and neighborhood density on receptive and expressive measures of learning (Storkel, 2001; Storkel \& Maekawa, 2005). In addition, the high-density advantage was observed primarily for completely correct responses rather than for partially correct responses. If the effect were attributable to production, then the effect should have been observed for both types of responses.

Alternatively, neighborhood density may influence the ability to hold a novel sound sequence in working memory by determining the number of words from long-term memory that are activated during learning (Roodenrys \& Hinton, 2002). That is, high-density nonwords will activate more neighbors in long-term memory than low-density nonwords, strengthening the memory trace of high-density nonwords in working memory. A stronger memory trace in working memory may facilitate the creation of an accurate and detailed representation for high-density over low-density novel words. In this way, neighborhood density may influence the initial creation of a lexical representation of a novel word. However, if this were the case, we would expect to observe an effect of neighborhood density on early word learning rather than on later word learning. This prediction is counter to the observed results.

A final possibility is that the effect of neighborhood density on word learning may be specific to the integration that occurs during later word learning. Once a new lexical representation has been created, neighborhood density may influence the integration of the new representation with existing representations, and this may have consequences for stabilizing the new representation. Specifically, during integration with existing representations, the lexical representation of a high-density novel word will form connections with many other ex- 
isting lexical representations. Upon subsequent encounters with the novel word, the new lexical representation will be activated, and this in turn will activate other lexical representations. These lexical representations will activate phonological representations, which in turn will spread activation back to the corresponding lexical representations. This interactive process will strengthen the connections between the new lexical representation and phonological representations, increasing the likelihood that the representation and links will stabilize with fewer exposures. This same process will occur for a lowdensity novel word, but the amount of activation will be reduced because fewer lexical representations will be activated. As a result, more exposures to the novel word will be required for the new representation to stabilize.

The previous hypotheses are somewhat speculative for several reasons. First, a nonproduction task was not used as a measure of word learning. Thus, it is difficult to differentiate language production effects at test from word learning effects. Second, working memory was not directly examined to afford comparison to the word learning data. A study of this type would allow direct testing of the hypothesis that the influence of neighborhood density on word learning is mediated by working memory. Third, the formation of connections between new representations and existing representations was not explicitly tested, as was done in Gaskell and Dumay (2003). Examination of connections would provide a direct test of the hypothesis that the formation of these connections facilitates word learning. In addition, it would allow for an even stronger test of the hypothesis that neighborhood density influences later stages of word learning. Specifically, it is possible that neighborhood density influences earlier stages of word learning, but that this was not detected in the current study because only target-appropriate connections between representations were considered. That is, neighborhood density calculations were based on the target, even when partially correct responses were examined. It is possible that new partial representations do form connections to existing representations immediately and that this provides a benefit to word learning. However, the connections formed would likely be based on both the correct as well as the inaccurate or underspecified information in the partial representation, leading to both target-appropriate as well as target-inappropriate connections. An attempt to examine the specific connections being formed would provide evidence to support or refute this hypothesis. Finally, like Gaskell and Dumay, we indexed early versus late word learning via a performance measure (i.e., partially correct vs. completely correct responses), albeit a different performance measure (i.e., type of response vs. different tasks). A performance measure was selected over a time-based measure (e.g., number of exposures) because of the between participant variability at each ex- posure. Given this variability, it was assumed that examining word learning at a given exposure would not guarantee that each individual participant was in the same stage of word learning. Additional research is needed to identify the measure that best indexes early versus later word learning. In undertaking this research, it will be important to consider a variety of both time and performance measures.

\section{Comparison to Past Adult Word Learning Studies}

In terms of comparison to the previous study of Gaskell and Dumay (2003), it is important to note that we hypothesized that integration of new representations with old representations may have occurred during the course of this study. This claim is somewhat at odds with findings from Gaskell and Dumay, in which integration occurred only after a delay of several days. We did not specifically test for integration of new and old representations, thus our hypotheses are tentative. However, it is possible that integration did occur because of several differences between the methods in the current study and those of Gaskell and Dumay. In particular, the current study paired nonwords with novel objects, whereas Gaskell and Dumay presented nonwords without any referents. The current study presented the nonwords in the meaningful context of a story, whereas Gaskell and Dumay presented nonwords in a decontextualized phoneme-monitoring task. The current study presented a smaller number of shorter nonwords in a set as compared with Gaskell and Dumay. These differences may have facilitated word learning in the current study, leading to faster creation and integration of representations of novel words. Future work systematically varying exposure conditions may aid in identifying the factors that influence the integration of new representations with existing representations during word learning.

\section{Conclusions}

Investigation of the influence of phonotactic probability on adult word learning yielded a high-probability disadvantage that may be accounted for by assuming that phonological representations influence novelty detection, thereby triggering new learning. In contrast, the effect of neighborhood density on adult word learning entailed a high-density advantage that appeared consistent with the hypothesis that lexical representations influence word learning directly by affecting stabilization of the new representation, although alternative hypotheses related to language production and working memory could not be completely ruled out. Current models of word learning do not appear to account fully for these 
findings because they are either too narrow, accounting for a set of specific effects (e.g., Samuelson, 2002), or too broad, lacking specificity in word learning mechanisms (e.g., Gupta \& MacWhinney, 1997; Plunkett, Sinha, Moller, \& Strandsby, 1992). The current findings indicate a need to consider the factors that influence the triggering of new learning as well as the integration of new representations.

\section{Acknowledgments}

This research was supported by National Institute on Deafness and Other Communication Disorders Grants DC-04781, DC-00052, and DC-06749. The following individuals contributed to stimulus preparation: Wade Burtchet, Jill Hoover, Kristen Linnemeyer, Andrea Perdue, Maki Sueto, and Junko Young. Michael Vitevitch provided helpful discussion of these findings.

\section{References}

Beckman, M. E., \& Edwards, J. (2000). Lexical frequency effects on young children's imitative productions. In M. B. Broe \& J. B. Pierrehumbert (Eds.), Papers in laboratory phonology $V$ (pp. 208-218). Cambridge, England: Cambridge University Press.

Capone, N. C., \& McGregor, K. (2005). The effect of semantic representation on toddlers' word retrieval. Journal of Speech, Language, and Hearing Research, 48, 1468-1480.

Carpenter, G. A., \& Grossberg, S. (1987). A massively parallel architecture for a self-organizing neural pattern recognition machine. Computer Vision, Graphics, and Image Processing, 37, 54-115.

DeBrunhoff, L. (1981). Babar's anniversary album. New York: Random House.

Dell, G. S. (1988). The retrieval of phonological forms in production: Tests of predictions from a connectionist model. Journal of Memory and Language, 27, 124-142.

Edwards, J., Beckman, M., \& Munson, B. (2004). The interaction between vocabulary size and phonotactic probability effects on children's production accuracy and fluency in nonword repetition. Journal of Speech, Language, and Hearing Research, 47, 421-436.

Frisch, S. A., Large, N. R., \& Pisoni, D. B. (2000). Perception of wordlikeness: Effects of segment probability and length on the processing of nonwords. Journal of Memory and Language, 42, 481-496.

Garlock, V. M., Walley, A. C., \& Metsala, J. L. (2001). Age-ofacquisition, word frequency, and neighborhood density effects on spoken word recognition by children and adults. Journal of Memory and Language, 45, 468-492.

Gaskell, M. G., \& Dumay, N. (2003). Lexical competition and the acquisition of novel words. Cognition, 89, 105-132.

Gathercole, S. E., Frankish, C. R., Pickering, S. J., \& Peaker, S. (1999). Phonotactic influences on short-term memory.
Journal of Experimental Psychology: Learning, Memory, and Cognition, 25, 84-95.

Geisel, T. S., \& Geisel, A. S. (1954). Horton hears a who! New York: Random House.

Geisel, T. S., \& Geisel, A. S. (1958). Cat in the hat comes back. New York: Random House.

German, D. J., \& Newman, R. S. (2004). The impact of lexical factors on children's word finding errors. Journal of Speech, Language, and Hearing Research, 47, 624-636.

Gupta, P., \& MacWhinney, B. (1997). Vocabulary acquisition and verbal short-term memory: Computational and neural bases. Brain and Language, 59, 267-333.

Jarvis, B. G. (2002). DirectRT research software (Version 2002) [Computer software]. New York: Empirisoft.

Levelt, W. J. M. (1989). Speaking: From intention to articulation. Cambridge, MA: MIT Press.

Luce, P., \& Large, N. R. (2001). Phonotactics, density, and entropy in spoken word recognition. Language and Cognitive Processes, 16, 565-581.

Luce, P. A., Goldinger, S. D., Auer, E. T., \& Vitevitch, M. S. (2000). Phonetic priming, neighborhood activation, and PARSYN. Perception \& Psychophysics, 62, 615-625.

Luce, P. A., \& Pisoni, D. B. (1998). Recognizing spoken words: The neighborhood activation model. Ear \& Hearing, 19, $1-36$.

Magnuson, J. S., Tanenhaus, M. K., Aslin, R. N., \& Dahan, D. (2003). The time course of spoken word learning and recognition: Studies with artificial lexicons. Journal of Experimental Psychology: General, 132, 202-227.

Mayer, M. (1992). Professor wormbog in search for the zipperumpa-zoo. Vancouver, Canada: Rainbird Press.

McClelland, J., \& Elman, J. (1986). The TRACE model of speech perception. Cognitive Psychology, 18, 1-86.

Metsala, J. L. (1997). An examination of word frequency and neighborhood density in the development of spoken-word recognition. Memory \& Cognition, 25, 47-56.

Munson, B. (2001). Phonological pattern frequency and speech production in adults and children. Journal of Speech, Language, and Hearing Research, 44, 778-792.

Munson, B., Edwards, J., \& Beckman, M. (2005). Relationships between nonword repetition accuracy and other measures of linguistic development in children with phonological disorders. Journal of Speech, Language, and Hearing Research, $48,61-78$.

Munson, B., Kurtz, B., \& Windsor, J. (2005). The influence of vocabulary size, phonotactic probability, and wordlikeness on nonword repetitions of children without specific language impairment. Journal of Speech, Language, and Hearing Research, 48, 1033-1047.

Munson, B., Swenson, C., \& Manthei, S. (2005). Lexical and phonological organization in children: Evidence from repetition tasks. Journal of Speech, Language, and Hearing Research, 48, 108-124.

Newman, R. S., \& German, D. J. (2002). Effects of lexical factors on lexical access among typical language-learning children and children with word-finding difficulties. Language and Speech, 45, 285-317. 
Newman, R. S., \& German, D. J. (2005). Life span effects on lexical factors in oral naming. Language and Speech, 48, 123-156.

Norris, D. G. (1994). SHORTLIST: A connectionist model of continuous speech recognition. Cognition, 52, 189-234.

Plunkett, K., Sinha, C., Moller, M. F., \& Strandsby, O. (1992). Symbol grounding or the emergence of symbols? Vocabulary growth in children and a connectionist net. Connection Science, 4, 293-312.

Roodenrys, S., \& Hinton, M. (2002). Sublexical or lexical effects on serial recall of nonwords? Journal of Experimental Psychology: Learning, Memory, and Cognition, 28, 29-33.

Samuelson, L. K. (2002). Statistical regularities in vocabulary guide language acquisition in connectionist models and 15-20-month-olds. Developmental Psychology, 38, 1016-1037.

Storkel, H. L. (2001). Learning new words: Phonotactic probability in language development. Journal of Speech, Language, and Hearing Research, 44, 1321-1337.

Storkel, H. L. (2003). Learning new words: II. Phonotactic probability in verb learning. Journal of Speech, Language, and Hearing Research, 46, 1312-1323.

Storkel, H. L. (2004a). The emerging lexicon of children with phonological delays: Phonotactic constraints and probability in acquisition. Journal of Speech, Language, and Hearing Research, 47, 1194-1212.

Storkel, H. L. (2004b). Methods for minimizing the confounding effects of word length in the analysis of phonotactic probability and neighborhood density. Journal of Speech, Language, and Hearing Research, 47, 1454-1468.

Storkel, H. L., \& Maekawa, J. (2005). A comparison of homonym and novel word learning: The role of phonotactic probability and word frequency. Journal of Child Language, $32,827-853$.

Storkel, H. L., \& Rogers, M. A. (2000). The effect of probabilistic phonotactics on lexical acquisition. Clinical Linguistics $\mathcal{E}$ Phonetics, 14, 407-425.
Thorn, A. S. C., \& Frankish, C. R. (2005). Long-term knowledge effects on serial recall of nonwords are not exclusively lexical. Journal of Experimental Psychology: Learning, Memory, and Cognition, 31, 729-735.

Vitevitch, M. S. (1997). The neighborhood characteristics of malapropisms. Language and Speech, 40, 211-228.

Vitevitch, M. S. (2002a). The influence of phonological similarity neighborhoods on speech production. Journal of Experimental Psychology: Learning, Memory, and Cognition, 28, 735-747.

Vitevitch, M. S. (2002b). Naturalistic and experimental analyses of word frequency and neighborhood density effects in slips of the ear. Language and Speech, 45, 407-434.

Vitevitch, M. S., Armbruster, J., \& Chu, S. (2004). Sublexical and lexical representations in speech production: Effects of phonotactic probability and onset density. Journal of Experimental Psychology: Learning, Memory, and Cognition, 30, 1-16.

Vitevitch, M. S., \& Luce, P. A. (1998). When words compete: Levels of processing in perception of spoken words. Psychological Science, 9, 325-329.

Vitevitch, M. S., \& Luce, P. A. (1999). Probabilistic phonotactics and neighborhood activation in spoken word recognition. Journal of Memory of Language, 40, 374-408.

Vitevitch, M. S., Luce, P. A., Charles-Luce, J., \& Kemmerer, D. (1997). Phonotactics and syllable stress: Implications for the processing of spoken nonsense words. Language and Speech, 40, 47-62.

Vitevitch, M. S., Luce, P. A., Pisoni, D. B., \& Auer, E. T. (1999). Phonotactics, neighborhood activation, and lexical access for spoken words. Brain and Language, 68, 306-311.

Webster's seventh new collegiate dictionary. (1967). Los Angeles: Library Reproduction Service. 
Appendix: Sample story episode.

Story $1 \quad$ Story 2

\begin{tabular}{|c|c|c|c|c|}
\hline Episode 1 & & \\
\hline Scene 1 & $\begin{array}{l}\text { Girl monster character } \\
\text { sitting on floor next to } \\
\text { couch crying. Boy monster } \\
\text { character standing next to } \\
\text { couch. }\end{array}$ & $\begin{array}{l}\text { Mom and dad were at work. } \\
\text { Big Brother had to take care } \\
\text { of Little Sister. Little Sister } \\
\text { was crying. “'ll take you to } \\
\text { the park if you stop crying," } \\
\text { said Big Brother. }\end{array}$ & $\begin{array}{l}\text { Girl crocodile character } \\
\text { talking and boy crocodile } \\
\text { character listening. }\end{array}$ & $\begin{array}{l}\text { Mary and Joe crocodile had } \\
\text { to go to school. Today was } \\
\text { a big day. It was show and } \\
\text { tell day. Mary and Joe were } \\
\text { looking for things to bring. }\end{array}$ \\
\hline Scene 3 & $\begin{array}{l}\text { Boy character standing } \\
\text { and holding punch toy. } \\
\text { Girl character sitting and } \\
\text { holding cork gun. }\end{array}$ & 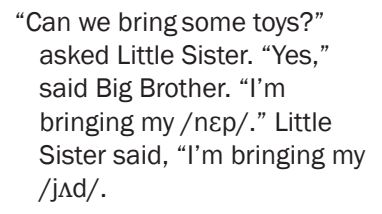 & $\begin{array}{l}\text { Girl character standing and } \\
\text { holding punch arrow. Boy } \\
\text { character standing and } \\
\text { holding marshmallow } \\
\text { sprayer. }\end{array}$ & $\begin{array}{l}\text { "Can we bring some toys?" } \\
\text { asked Joe. "Yes," said Mary. } \\
\text { “l'm bringing my /joon/." } \\
\text { Joe said, "I'm bringing my } \\
\text { /ferg/." }\end{array}$ \\
\hline Scene 4 & $\begin{array}{l}\text { Boy character standing } \\
\text { blowing on orange trumpet } \\
\text { with bell pointing down. Girl } \\
\text { character in profile blowing } \\
\text { on yellow hand-held tuba. }\end{array}$ & $\begin{array}{l}\text { “We can play music at the } \\
\text { park," said Big Brother. "I’m } \\
\text { taking my /jib/." Little Sister } \\
\text { said, "I'm taking my / hif/." }\end{array}$ & $\begin{array}{l}\text { Girl character in profile } \\
\text { blowing on red saxophone } \\
\text { pointing down. Boy } \\
\text { character in profile blowing } \\
\text { blue oboe pointing up. }\end{array}$ & $\begin{array}{l}\text { “We can play music at show } \\
\text { and tell," said Mary. “I'm } \\
\text { taking my /mعk/." Joe said, } \\
\text { “l'm taking my /waf/." }\end{array}$ \\
\hline Scene 5 & $\begin{array}{l}\text { Boy character walking green } \\
\text { gerbil with antenna on } \\
\text { a leash. Girl character } \\
\text { carrying purple mouse-bat. }\end{array}$ & $\begin{array}{l}\text { “What about the pets?" asked } \\
\text { Little Sister. "We'll take } \\
\text { them with us," said Big } \\
\text { Brother. "I'll get / paib/." } \\
\text { Little Sister said, "I'll get } \\
\text { /wæd/." }\end{array}$ & $\begin{array}{l}\text { Girl character holding yellow } \\
\text { frog bat. Boy character } \\
\text { walking orange elephant- } \\
\text { mouse on leash. }\end{array}$ & $\begin{array}{l}\text { “Can we bring our pets?" } \\
\text { asked Joe. "Sure," said } \\
\text { Mary. "I'll get /mug/." Joe } \\
\text { said, "I'll get / navt/." }\end{array}$ \\
\hline
\end{tabular}

There were three additional alternative versions of this story episode to achieve counterbalancing in pairing nonwords with referents across participants. In addition, the order of presentation of Scenes 2-5 was randomized across participants. 